\title{
Auricular Myoclonus
}

\author{
Andrew Kirk and Kenneth M. Heilman
}

\begin{abstract}
We describe a young man with a two and a half year history of idiopathic irregular contractions of an antitragicus muscle in the absence of a more generalized movement disorder. These contractions persisted in sleep and could not be replicated voluntarily. Because proximal nerve block temporarily eliminated the movements and complex hand movements reduced their amplitude and frequency, we suspect a central generator. However, these movements were not associated with any known pathologic condition.
\end{abstract}

RÉSUMÉ: Myoclonus auriculaire Nous décrivons le cas d'un jeune homme qui présentait, depuis deux ans et demi, des contractions irrégulières idiopathiques du muscle de l'antitragus en l'absence d'un désordre du mouvement plus généralisé. Ces contractions persistaient pendant le sommeil et ne pouvaient pas être reproduites volontairement. Nous soupçonnons un site générateur central parce qu'un bloc nerveaux proximal a éliminé temporairement le myoclonus et que les mouvements manuels complexes en réduisaient l'amplitude et la fréquence. Cependant, ce myoclonus n'était pas associé à une condition pathologique connue.

Can. J. Neurol. Sci. 1991; 18: 503-504

Movement disorders involving the external ear have not been commonly reported. We describe a case of irregular clonic movements of the antitragicus muscle, persisting during sleep.

\section{Case Report}

A 20-year-old left-handed university student presented with a two year history of involuntary movements of his right ear. Initially, these had been intermittent and he had been particularly aware of them while talking on the telephone with the receiver against his ear. After six months the movements became constant during all activities. He had difficulty falling asleep because of the ear movements and had been told that they persisted during sleep. There was no tinnitus (clicking or otherwise). He noted no hearing impairment and denied any other motor or sensory symptoms. He had never noted any abnormal movements of the other ear, or of the face, mouth, or throat. There were no previous neurologic symptoms. At age 7 he had suffered an uncomplicated otitis media but could not recall which ear had been affected. He was taking no medications and denied illicit drug use. The patient had no known toxin exposure. There was no family history of neurologic disorders. He had never been able to voluntarily wiggle his ears. There was no history of or evidence for a psychiatric disorder.

Findings of general physical and mental status examinations were normal. Cranial nerve examination revealed no abnormality apart from movement of the right ear. There were irregular clonic movements in which the antitragus and antihelix were approximated. These were oddly reminiscent of the openings and closings of a fish's gill and were compatible with isolated contractions of the antitragicus muscle, which is innervated by the facial nerve. No movements were seen in the scalp, face, contralateral ear, tongue, palate, pharynx, or elsewhere. Although irregular, the ear movements occurred consistently at an overall rate of 70-75 per minute. They were not synchronous with his pulse. Mental arithmetic and other cognitive tasks had no effect on these auricular movements. They persisted unchanged during talking, swallowing, and facial and head movements but could be reduced in amplitude and fre- quency by having him perform complex repetitive movements with either hand. Even so, the movements were never absent for more than five seconds. Although he felt that he could reduce the movement by intense concentration, we were unable to appreciate any change. Hearing was normal. Motor, sensory, and reflex examinations were normal as were coordination and gait. Plantar responses were flexor.

A surface electrode over the antitragus revealed irregular brief bursts of synchronous firing by several motor units simultaneous with the visible movements. Complex repetitive hand movements caused these bursts to be less frequent and of lower amplitude. MRI scan of head was normal. Serum ceruloplasmin, antinuclear antibody, rheumatoid factor, syphilis serology, blood count, and routine biochemical studies were normal.

A premastoid facial nerve block with $4 \mathrm{~mL}$ of $2 \%$ lidocaine resulted in complete cessation of the movements for the duration of the facial paralysis. A therapeutic trial of an oral medication or of a local therapy, such as botulinum toxin, might have proven effective. The patient, however, declined any pharmacologic intervention, explaining that he could tolerate the movements themselves, as long as they were not a manifestation of any more serious illness. When last seen in follow-up, two and a half years after the onset of the ear movements, he remained otherwise well.

\section{Comment}

Because facial nerve block eliminated these movements, we do not believe they arose from an abnormality of the distal nerve or muscle. Although we cannot discount the possibility that the movements originated in the proximal nerve, their diminution during complex hand movements suggests that they were subject to modulating influences within the central nervous system and arose there rather than in the periphery.

The intrinsic muscles of the external ear are not normally under voluntary control ${ }^{1}$ although many people can wiggle their

From the Department of Neurology, University of Florida College of Medicine, and the Veterans Administration Medical Center, Gainesville, Florida Received December 3, 1990. Accepted in final form May 19, 1991

Reprint requests to: Andrew Kirk, Department of Medicine, Division of Neurology, College of Medicine, University of Saskatchewan, Saskatoon, Saskatchewan, Canada S7N 0X0 
ears using extrinsic and scalp muscles. ${ }^{2}$ Movement disorders involving solely the auricle have rarely been reported. Keshavan ${ }^{3}$ described ten cases of ear tics but these differed from the present case in several respects. Keshavan's patients all had bilateral intermittent symptoms while awake and exhibited some degree of voluntary control over the movements. Their movements were attributable to contractions of extrinsic rather than intrinsic musculature and in most cases scalp movements were also present. His patients, unlike ours, often exhibited signs of psychiatric illness and improved with psychotherapy. Although tics may persist during sleep in Tourette's syndrome, ${ }^{4}$ our patient had no other features to suggest this disorder. Tics often imitate coordinated voluntary acts and are often multiple rather than being isolated contractions of a vestigial ear muscle. ${ }^{5}$

Hemifacial spasm usually affects older patients and begins about the eye and mouth. 6 We are unaware of any reports of hemifacial spasm starting in the ear.

This patient's movement disorder is probably best characterized as myoclonus - an irregular, involuntary, shock-like movement. ${ }^{7}$ Palatal myoclonus can involve areas distant from the palate. 8 Although facial muscles may be involved and Eustachian tinnitus may result from the palatal movements, ${ }^{9}$ no reports mention spread to intrinsic auricular muscles. Although usually faster than the present case, palatal myoclonus may occur at rates of $40-600$ per minute. ${ }^{10,11}$ Palatal myoclonus typically persists during sleep ${ }^{12}$ and, even though classically described as inexorably persistent, ${ }^{13}$ variability and intermittency have been described. ${ }^{11}, 14$ Some cases of palatal myoclonus, unlike this case, abate during swallowing and phonation. 13 Palatal myoclonus may result from any of a variety of lesions within the Guillain-Mollaret triangle. 15 The present patient had no evidence for infarction, ${ }^{16}$ tumor, ${ }^{17}$ trauma, ${ }^{18}$ or plaque ${ }^{18}$ within this system. Olivary hypertrophy was not evident on MRI $^{19}$ and he had no other signs to support the possibility of a degenerative disease of the nervous system. ${ }^{19}$ Most of these disorders could not be entirely ruled out.

Although the present patient's movement disorder may represent an unusual variant of any one of the disorders discussed above, it does not seem that intrinsic auricular movements like those described here have been previously noted. We suspect that this disorder represents focal myoclonus of brainstem origin although some classification systems 20,21 do not explicitly recognize such an entity as distinct from palatal myoclonus. As no pathologic explanation for this patient's movements was evident, one can only speculate whether this represents a distinct clinical entity. Correlation with future cases of auricular movements in patients with and without abnormal movements elsewhere may establish the relationships between this and other disorders of movement.

\section{ACKNOWLEDGEMENT}

This work was supported by the Medical Research Service of the Veterans Administration.

\section{REFERENCES}

1. Donaldson JA, Miller JM. Anatomy of the ear. In: Paparella MM, Shumrick DA, eds. Otolaryngology. Philadelphia: Saunders, 1980: 26-62.

2. Clemente CD, ed. Gray's Anatomy. Philadelphia: Lea and Febiger, 1985: 441 .

3. Keshavan MS. The ear wigglers: Tics of the ear in 10 patients. Am J Psychiatry 1988; 145: 1462-1463.

4. Glaze DG, Frost JD, Jr, Jankovic J. Sleep in Gilles de la Tourette's syndrome: disorder of arousal, Neurology 1983; 33: 586-592.

5. Weingarten K. Tics. In: Vinken PJ, Bruyn GW, eds. Handbook of Clinical Neurology. Amsterdam, North-Holland, 1968: 728-808.

6. Auger RG. Hemifacial spasm: Clinical and electrophysiologic observations. Neurology 1979; 29: 1261-1272.

7. Swanson PD, Luttrell CN, Magladeny JW. Myoclonus - a report of 67 cases and review of the literature. Medicine 1962; 41: 339356.

8. Riley HA, Brock S. Rhythmic myoclonus of the muscles of the palate, pharynx, larynx and other regions: a clinical report of three cases. Arch Neurol Psychiatry 1933; 29: 726-741.

9. Bjork H. Objective tinnitus due to clonus of the soft palate. Acta Otolaryngol 1954; 116 (suppl): 39.

10. Tahinoush AJ, Brooks JE, Keltner JL. Palatal myoclonus associated with abnormal ocular and extremity movements - a polygraph ic study. Arch Neurol 1972; 27: 431-440.

11. Kayed K, Sjaastad O, Magnussen I, Marvik R. Palatal myoclonus during sleep. Sleep 1983; 6: 130-136.

12. Nathanson M. Palatal myoclonus: further clinical and pathophysiologic observations. Arch Neurol Psychiatry 1956; 75: 285-296.

13. Bender MB, Nathanson M, Gordon GG. Myoclonus of muscles of the eye, face, and throat. Arch Neurol Psychiatry 1952; 57: 4458.

14. Jacobs L, Newman RP, Bozian D. Disappearing palatal myoclonus. Neurology 1981; 31: 748-751.

15. Guillain G, Mollaret P. Nouvelle contribution a l'étude des myoclonies vélo-pharyngo-laryngo-diaphragmatiques. Rev Neurol 1932; 2: 249-264.

16. Freeman W. Palatal myoclonus - report of two cases with necropsy. Arch Neurol Psychiatry 1933; 29: 742-755.

17. Spencer HR. Pharyngeal and laryngeal "nystagmus". Lancet 1886; 2: 702 .

18. Herrmann C, Jr, Brown JW. Palatal myoclonus: a reappraisal. J Neurol Sci 1967; 5: 473-492.

19. Sperling MR, Herrmann C, Jr. Syndrome of palatal myoclonus and progressive ataxia - two cases with magnetic resonance imaging. Neurology 1985; 35: 1212-1214.

20. Hallett M. Myoclonus: relation to epilepsy. Epilepsia 1985; 26 (suppl. 1): S67-S77.

21. Hallett M. The pathophysiology of myoclonus. TINS 1987; 10: 69-73. 